\title{
Antimicrobial effect of porcelain glaze with silver-clay antimicrobial agent
}

\author{
Hideki YOSHIDA, ${ }^{\dagger}$ Hisao ABE, Toshitsugu TAGURI, ${ }^{*}$ Fumihiko OHASHI, ${ }^{* *}$ \\ Shigeru FUJINO ${ }^{* * *}$ and Toshihisa KAJIWARA ${ }^{* * *}$ \\ Ceramic Research Center of Nagasaki, 605-2 Hiekoba-go, Hasami-cho, Higashisonogi-gun, Nagasaki 859-3726 \\ *Department of Microbiology, Nagasaki Prefectural Institute for Environmental Research and Public Health, \\ 2-1306-11 Ikeda, Omura, Nagasaki 856-0026 \\ ** Materials Research Institute for Sustainable Development, National Institute of Advanced Industrial \\ Science and Technology (AIST), Shimo-Shidami, Moriyama, Nagoya 463-8560 \\ *** Department of Chemical Engineering, Faculty of Engineering, Kyushu University, 744 Motooka, Nishi-ku, Fukuoka $819-0395$
}

Antimicrobial activities of porcelain glazes with antimicrobial agents made of clay minerals intercalated with silver chelate and the effect of additives to the antimicrobial agents on those activities were investigated. The glazes with 10 mass \% antimicrobial agents, fired at $1573 \mathrm{~K}$ in a reducing atmosphere, showed negative antimicrobial activities. On the other hand, the antimicrobial activities of the glazes with 1-10 mass \% of the agents fired in an oxidizing atmosphere were positive. The glaze with an agent doped with $\mathrm{Zr}$ had a high antimicrobial activity by adding only 0.2 mass $\%$ of the agent, which included only $0.008 \mathrm{mass} \%$ Ag in the glaze. Wavelength-dispersive $X$-ray fluorescence, used for ingredient analysis, showed that the negative activity resulted from the disappearance of the $\mathrm{Ag}$ in the glaze fired in the reducing atmosphere.

(2010 The Ceramic Society of Japan. All rights reserved.

Key-words : Silver-clay antimicrobial agent, Porcelain product, Porcelain glaze, Antimicrobial activity, Firing atmosphere

[Received December 21, 2009; Accepted May 20, 2010]

\section{Introduction}

According to the statistics on food poisoning, ${ }^{1)}$ published by the Ministry of Health, Labor, and Welfare, the total number of incidents of food poisoning in Japan in 2008 amounted to 1,369 and the total number of patients amounted to 24,303 . Of the total cases, 778 were caused by bacteria, accounting for $56.8 \%$, followed by viruses $(22.2 \%)$, natural toxins (11.1\%), and the others $(9.9 \%)$. In recent years, the incidence has not yet decreased; therefore, large cooking facilities, e.g., schools, social-welfare facilities, and restaurants, are required to undergo a thorough sanitation process.

Due to the increasing value placed on comfort and cleanliness, interest in the antimicrobial treatment of tableware is growing. Sanitaryware is known as antimicrobial-treated ceramics, but there is little evidence of successful antimicrobial treatment for tableware because of the requirement for different firing conditions. Porcelain tableware produced in the Hizen region of Japan was fired at $1573 \mathrm{~K}$ in a reducing atmosphere containing $\mathrm{CO}$ gas, whereas sanitaryware was fired at about $1473 \mathrm{~K}$ in an oxidizing atmosphere.

To create bluish-white porcelain, iron compounds (mainly $\mathrm{Fe}_{2} \mathrm{O}_{3}$ ) contained in raw materials are reduced to $\mathrm{FeO}$ by reduction firing. So, it is necessary to consider how the new antimicrobial treatment can be applied in such a firing process.

Both organic and inorganic antimicrobial agents are commercially available. Because ceramic products required a heattreatment process, a heat-resistant inorganic antimicrobial agent is required. Various inorganic agents, which based on glass, ${ }^{2)}$ zeolite, ${ }^{3)}$ and apatite matrices, ${ }^{4)}$ among others, are commercially

\footnotetext{
Corresponding author: H. Yoshida; E-mail: yoshida@cren.jp
}

available. Recently, an antimicrobial agent derived from montmorillonite intercalated with a $\mathrm{Ag}$ chelate of $\mathrm{Ag}^{+}(\mathrm{TBZ})_{2}$ has been developed. ${ }^{5), 6)}$ The schematic of this antimicrobial agent is shown in Fig. 1. Originally, the aim of introducing $\mathrm{Ag}^{+}(\mathrm{TBZ})_{2}$ into the interlayer space of the montmorillonite was the long-

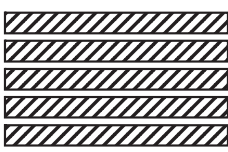

Layer structure of

montmorillonite
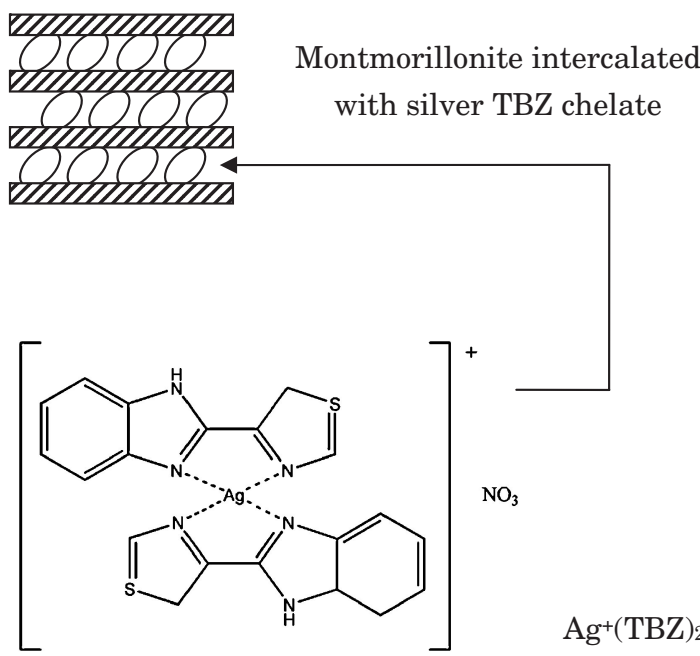

$\mathrm{Ag}^{+}(\mathrm{TBZ})_{2}$ chelate

Fig. 1. Schematic of montmorillonite intercalated with $\mathrm{Ag}^{+}(\mathrm{TBZ})_{2}$ chelate. 
term release of antimicrobial and antifungal agents. However, the structure may have heat resistance, because it has mineral frames of aluminosilicate. Although the montmorillonite intercalated with $\mathrm{Ag}^{+}(\mathrm{TBZ})_{2}$ added to a glaze is thermally decomposed after high-temperature firing, Ag elements will be dispersed in the glaze and indicate an antimicrobial effect. In addition, other elements, for example, $\mathrm{Al}$ and $\mathrm{Zr}$ can be co-doped into the interlayer spaces of montmorillonite to improve heat resistance, which are often used for improvement of the thermal stability of inorganic pigment for ceramics. ${ }^{7), 8)}$ But there are no data in the literature regarding the antimicrobial effects of porcelain glaze with a silver-clay antimicrobial agent.

In this study, antimicrobial activities of the porcelain glaze with an antimicrobial agent, generally used in the Hizen region of Japan, were investigated. In addition, in order to improve the antimicrobial activity after high-temperature firing, the co-doping effect of $\mathrm{Al}$ and $\mathrm{Zr}$ into the interlayer spaces of montmorillonite was also examined.

\section{Experimental procedure}

\subsection{Preparation of silver-clay antimicrobial agents for porcelain}

As details of preparation of the agents were given in a previous paper, ${ }^{5)}$ only a brief outline is described below.

Na-montmorillonite (trade name Kunipia-F) was provided by Kunimine Ind. and has the typical chemical formula of $\mathrm{Na}^{0.66+}\left[\left(\mathrm{Al}_{3.33} \mathrm{Mg}_{0.67}\right)\left(\mathrm{Si}_{8} \mathrm{O}_{20}\right)(\mathrm{OH})_{4}\right]^{0.66-}$. A chemical grade organic ligand, 2-(4-thiazolyl)-benzimidazole (TBZ, Tokyo Chemical Industry Co., Ltd.) and silver nitrate $\left(\mathrm{AgNO}_{3}\right.$, Wako Pure Chemical Industries, Ltd.) were used as the chelate ingredients. The flow chart of the preparation of montmorillonite intercalated with $\mathrm{Ag}^{+}(\mathrm{TBZ})_{2}$ chelate is shown in Fig. 2. $\mathrm{Ag}^{+}(\mathrm{TBZ})_{2} /$ Mont in this figure shows the composite consisting of silver chelate and montmorillonite.

Polynuclear hydroxide cations of aluminum $\left(\mathrm{Al}_{2}(\mathrm{OH})_{5} \mathrm{Cl}\right.$. $2 \mathrm{H}_{2} \mathrm{O}$, Taki Chemical Co., Ltd.) and zirconium $\left(\mathrm{ZrOCl}_{2} \cdot 8 \mathrm{H}_{2} \mathrm{O}\right.$, Wako Pure Chemical Industries, Ltd.) were used as additives. $\left[\mathrm{Al}_{13} \mathrm{O}_{4}(\mathrm{OH})_{24}\right]^{7+}$ and $\left[\mathrm{Zr}_{4}(\mathrm{OH})_{14}\right]^{2+}$ ions were generated by dissolving the polynuclear hydroxide cations in water, and the ions were intercalated into the montmorillonite interlayer space. Because the cation exchange capacity (CEC) of the

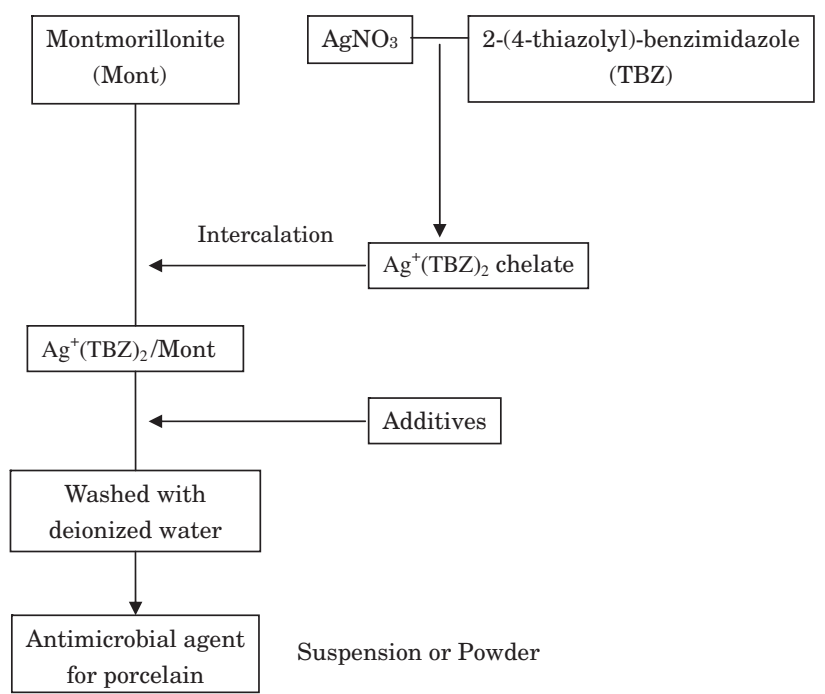

Fig. 2. Flow diagram of the synthesis of montmorillonite intercalated with $\mathrm{Ag}^{+}(\mathrm{TBZ})_{2}$ chelate.
Table 1. Sample names and Ag contents of antimicrobial agents derived from clay minerals

\begin{tabular}{lcccc}
\hline $\begin{array}{l}\text { Sample name } \\
\text { Ag content }\end{array}$ & Ag25\%A175\% & Ag50\%A150\% & Ag75\%A125\% & Ag100\% \\
(mass \%) & 2.0 & 3.8 & 3.9 & 4.4 \\
\hline $\begin{array}{l}\text { Sample name } \\
\text { Ag25\%Zr75\% }\end{array}$ & $\mathrm{Ag} 50 \% \mathrm{Zr} 50 \%$ & $\mathrm{Ag} 75 \% \mathrm{Zr} 25 \%$ & \\
$\begin{array}{l}\text { Ag content } \\
\text { (mass } \%)\end{array}$ & 1.9 & 3.1 & 4.0 & \\
\hline
\end{tabular}

Na-montmorillonite was $\left.108 \mathrm{cmol}(+) / \mathrm{kg},{ }^{6}\right)$ chemical equivalent weights of silver chelate and polynuclear hydroxide cations could be calculated in advance. The sample names of silver-clay antimicrobial agents and these $\mathrm{Ag}$ contents are shown in Table 1. They were in the range of 1.9 to 4.4 mass \%, which was less than half of commercial inorganic antimicrobial agents.

\subsection{Preparation of glaze with antimicrobial agents and firing of samples}

A glaze with Seger formula of $0.16 \mathrm{Na}_{2} \mathrm{O} \cdot 0.15 \mathrm{~K}_{2} \mathrm{O} \cdot 0.69 \mathrm{CaO}$. $0.55 \mathrm{~A}_{2} \mathrm{O}_{3} \cdot 4.5 \mathrm{SiO}_{2}$ in mole percent was used. 10 mass $\%$ equivalent dry weight of antimicrobial powder was added to the glaze-water suspension with 50 mass $\%$ concentrations. After stirring at $500 \mathrm{rpm}$ for $10 \mathrm{~min}$ using a planetary ball mill, the mixture was glazed on a biscuit sample of Amakusa clay. The glaze-water suspension without antimicrobial agent was also glazed on a similar sample. The samples were fired at $1573 \mathrm{~K}$ in the oxidizing and reducing atmospheres using an electric furnace and a gas furnace, respectively.

In oxidation firing, the samples were fired at $1573 \mathrm{~K}$ for $0.5 \mathrm{~h}$ in air. In reduction firing, the samples were heated up to $1273 \mathrm{~K}$ in complete combustion with excess air supply and were heated up to $1573 \mathrm{~K}$ in a reducing atmosphere of $3 \mathrm{vol} \% \mathrm{CO}$ gas generated by incomplete combustion with insufficient air supply. CO concentration was measured using a gas analyzer (ZFYBM111-D, Fuji Electric Instruments Co., Ltd.).

\subsection{Evaluation of antimicrobial activities}

The film contact method prescribed by the Society of Industrial Technology for Antimicrobial Articles ${ }^{9)}$ was employed for evaluation of antimicrobial activity. Briefly, Escherichia coli strain IFO 3972 (ATCC 8739) was purchased from the Institute for Fermentation Osaka (Osaka, Japan) and cultivated using normal agar (Eiken Chemical, Tokyo, Japan) at $37^{\circ} \mathrm{C}$ overnight. The strain was adjusted to ca. $1.0-5.0 \times 10^{5}$ cells $\mathrm{mL}^{-1}$ in an autoclaved $0.2 \%$ normal broth (Eiken Chemical) at $\mathrm{pH} 7.0 \pm 0.2$, and the suspension was applied to this test. Four hundred microliters of the suspension were inoculated on the surface of each sample, which were then covered by a film piece with sides of $40 \mathrm{~mm} \pm 2 \mathrm{~mm}$ from cutting the film bag (Organo Co., Tokyo, Japan). After incubation at $35^{\circ} \mathrm{C}$ for $24 \mathrm{~h}$, the viable bacterial counts were enumerated using the plate-counting method. The test was carried out in triplicate on both untreated samples and samples treated with an antimicrobial agent, and the mean values of viable counts for these samples were analyzed.

An antimicrobial activity, $R$, is calculated as follows:

$$
R=\left[\log \left(\frac{B}{A}\right)-\log \left(\frac{C}{A}\right)\right]=\left[\log \left(\frac{B}{C}\right)\right],
$$

where $A$ is the mean of the viable bacterial counts after inoculation of the untreated specimen; $B$, the mean of the viable bacterial counts of the untreated specimen after $24 \mathrm{~h}$; and $C$, the mean of the viable bacterial counts of the specimen treated with 
Table 2. Antimicrobial activities of the glazes with 10 mass $\%$ agents fired at $1573 \mathrm{~K}$ in the reducing atmosphere

\begin{tabular}{lcc}
\hline Sample name & Antimicrobial activity $(R)$ & Result \\
\hline Ag100\% & -0.1 & Negative \\
Ag25\%A175\% & 0.1 & Negative \\
Ag50\%A150\% & 0.0 & Negative \\
Ag75\%A125\% & 0.0 & Negative \\
Ag25\%Zr75\% & -0.1 & Negative \\
Ag50\%Zr50\% & 0.1 & Negative \\
Ag75\%Zr25\% & 0.2 & Negative \\
\hline
\end{tabular}

an antimicrobial agent after $24 \mathrm{~h} . R$ is the logarithmic value of antibacterial activity to antimicrobial goods in an antibacterial test method using bacteria with gentle growth. $R$ is positive when greater than 2.0 and negative when less than 2.0. E. coli with $0.2 \%$ normal broth usually shows an increase of almost 2 logged at $35^{\circ} \mathrm{C}$ for $24 \mathrm{~h}$, even though $E$. coli with $100 \%$ normal broth shows an increase of the same amount only after $2 \mathrm{~h}$. Therefore, a positive value indicates an inhibition of bacteriostatic growth, and a negative value indicates ineffective inhibition in the same stage. This method has been authorized by Japanese Industrial Standard Z 2801 from 2000.

\subsection{Analysis of silver in the glaze}

Qualitative and semi-quantitative analysis of $\mathrm{Ag}$ in the glazes with 10 mass $\%$ of the antimicrobial agents, with samples fired at $1573 \mathrm{~K}$ in the oxidizing or reducing atmosphere, was performed using a sequential wavelength-dispersive $\mathrm{X}$-ray fluorescence (XRF) spectrometer (MagiX PRO PW-2440/00, Philips) running at $60 \mathrm{kV}$ and $66 \mathrm{~mA}$. Philips Super Q software was used for semiquantitative analysis.

\section{Results and discussion}

\subsection{Antimicrobial activities of the samples fired in the reducing atmosphere}

The antimicrobial activities, $R$, of the glazes with 10 mass $\%$ antimicrobial agents fired at $1573 \mathrm{~K}$ in the reducing atmosphere are summarized in Table 2; the results of all samples were negative and all $R$ values were near zero, implying that the antimicrobial effects were completely lost. XRF profiles of the glaze surface of the samples fired at $1573 \mathrm{~K}$ in the oxidizing and reducing atmospheres are shown in Fig. 3. As shown in Fig. 3(b), the sample fired in the reducing atmosphere had no peaks. The loss of $\mathrm{Ag}$ in the glaze caused the loss of the antimicrobial effects.

A commercial inorganic antimicrobial agent consisting of calcium zinc phosphate showed similar results under the same firing conditions. It was considered that the loss of $\mathrm{Ag}$ by reduction firing is due to the reactivity of $\mathrm{Ag}$ with a reducing gas containing $\mathrm{CO}$ rather than the matrix of antimicrobial agent, which supported Ag. There are some articles ${ }^{10)-12)}$ on the reaction between $\mathrm{Ag}$ in various solutions and $\mathrm{CO}$ gas at room temperature, but nothing is written about the reaction of $\mathrm{Ag}$ in glass melts and $\mathrm{CO}$ gas at high temperature. The reason why $\mathrm{Ag}$ disappeared from the glaze by reduction firing is not clear at present.

\subsection{Antimicrobial activities of the samples fired in the oxidizing atmosphere and effect of additives to the antimicrobial agents}

$R$ values of the glazes with 10 mass \% antimicrobial agents fired at $1573 \mathrm{~K}$ in the oxidizing atmosphere are shown in
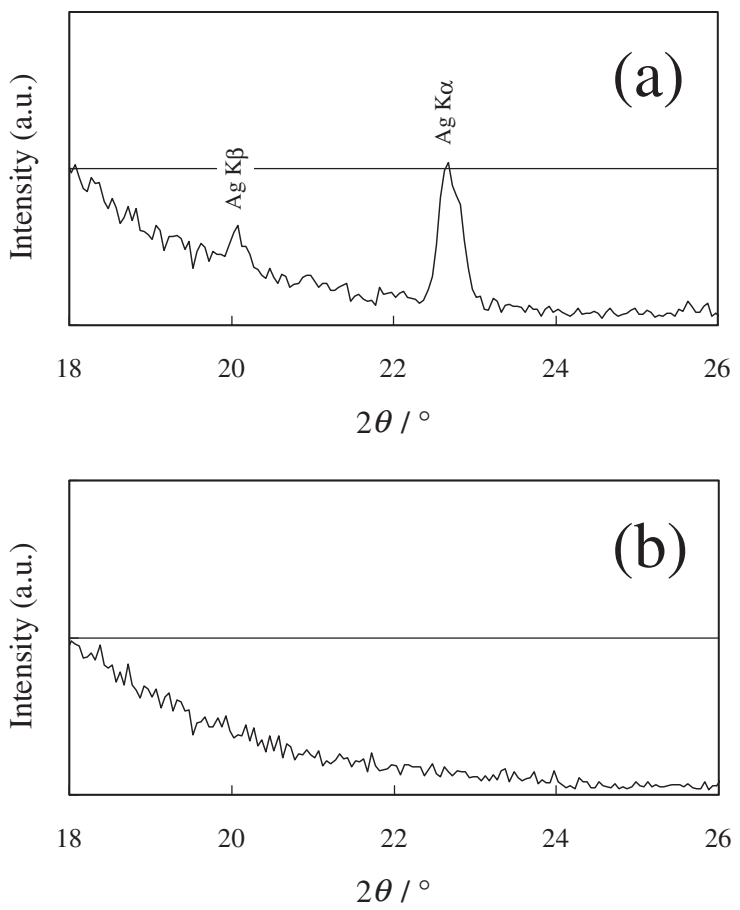

Fig. 3. XRF profiles of the glaze surface of samples fired at $1573 \mathrm{~K}$ in the (a) oxidizing and (b) reducing atmospheres.

Table 3. Antimicrobial activities of the glazes with 10 mass $\%$ agents fired at $1573 \mathrm{~K}$ in the oxidizing atmosphere

\begin{tabular}{lcl}
\hline Sample name & Antimicrobial activity $(R)$ & Result \\
\hline Ag100\% & 2.5 & Positive \\
Ag25\%A175\% & 2.5 & Positive \\
Ag50\%Al50\% & 2.6 & Positive \\
Ag75\%Al25\% & 2.7 & Positive \\
Ag25\%Zr75\% & 2.7 & Positive \\
Ag50\%Zr50\% & 2.7 & Positive \\
Ag75\%Zr25\% & 2.7 & Positive \\
\hline
\end{tabular}

Table 3. $R$ values of all the samples were in the range of 2.52.7, which indicated positive. Although the Ag content of the samples was in the range of 1.9-4.4 mass \%, which included $0.19-0.44$ mass $\%$ in the glazes, there was not much difference in the antimicrobial activities. As shown in Fig. 3(a), Ag clearly existed in the glaze with 10 mass $\%$ of the sample. As a result of semi-quantitative analysis by Super $\mathrm{Q}$ software, it was known that Ag content had been $0.046 \mathrm{wt} \%$, which showed that about $10 \%$ of $\mathrm{Ag}$ added to the glaze had remained.

Next, the amount of the antimicrobial agents was reduced to the range of $0.1-1.0$ mass $\%$, and antimicrobial activities were also measured. $R$ values of the glazes with $0.1-1.0$ mass $\%$ agents fired at $1573 \mathrm{~K}$ in the oxidizing atmosphere are shown in Table 4. Some samples with 1.0 mass $\%$ agent had $R$ values greater than 2.0. The relationship between the initial amounts of $\mathrm{Ag}$ doped in the prepared glaze before firing, calculated by multiplying the Ag content in the samples shown in Table 1 by the agent contents added to the glaze, and the $R$ values are shown in Fig. 4. Except for $\mathrm{Ag} 75 \% \mathrm{Zr} 25 \%, R$ values of the samples were decreased with decreasing the amount of Ag. On the other hand, despite the smaller addition of $\operatorname{Ag} 75 \% \mathrm{Zr} 25 \%$, it was clearly showed positive in the addition of only 0.2 mass $\%$ to the glaze, which included only 0.008 mass $\% \mathrm{Ag}$ in the glaze. The 
Table 4. Antimicrobial activities of the glazes with $0.1-1.0$ mass $\%$ agents fired at $1573 \mathrm{~K}$ in the oxidizing atmosphere

\begin{tabular}{lllll}
\hline \multirow{2}{*}{ Sample name } & \multicolumn{4}{c}{ Content of the agent (mass \%) } \\
\cline { 2 - 5 } & 0.1 & 0.2 & 0.5 & 1.0 \\
\hline Ag100\% & 0.1 (Negative) & 0.7 (Negative) & 1.0 (Negative) & $\mathbf{2 . 0}$ (Positive) \\
$\mathrm{Ag} 25 \% \mathrm{Al} 75 \%$ & 0.2 (Negative) & 0.2 (Negative) & 0.5 (Negative) & $\mathbf{2 . 0}$ (Positive) \\
$\mathrm{Ag} 50 \% \mathrm{~A} 150 \%$ & 0.5 (Negative) & 0.2 (Negative) & 0.1 (Negative) & 1.3 (Negative) \\
$\mathrm{Ag} 75 \% \mathrm{Al} 25 \%$ & 0.1 (Negative) & 0.2 (Negative) & 0.7 (Negative) & $\mathbf{2 . 2}$ (Positive) \\
$\mathrm{Ag} 25 \% \mathrm{Zr} 75 \%$ & 0.2 (Negative) & 0.2 (Negative) & 0.6 (Negative) & 1.0 (Negative) \\
$\mathrm{Ag} 50 \% \mathrm{Zr50 \%}$ & 0.2 (Negative) & 0.1 (Negative) & 0.4 (Negative) & 1.4 (Negative) \\
$\mathrm{Ag75 \% Zr25 \%}$ & 0.8 (Negative) & $\mathbf{2 . 5}$ (Positive) & $\mathbf{2 . 1}$ (Positive) & $\mathbf{2 . 6}$ (Positive) \\
\hline
\end{tabular}

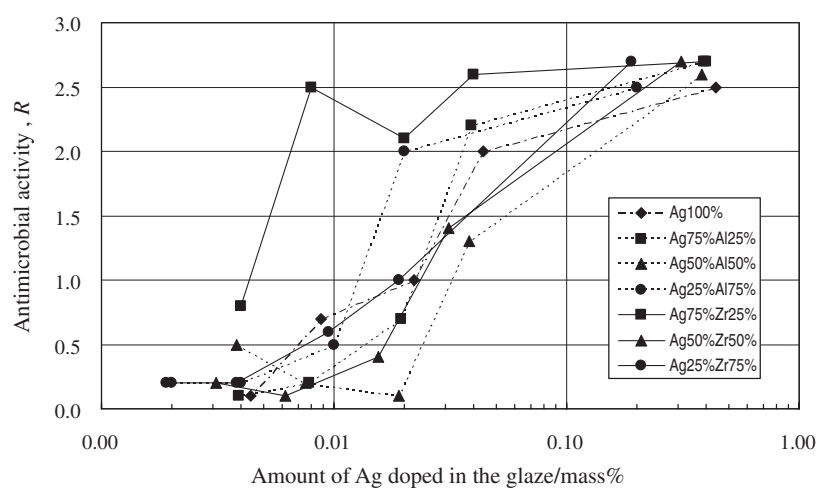

Fig. 4. Relationship between the initial amounts of Ag doped in the prepared glaze before firing, which were calculated by multiplying the Ag content in the samples by the agent contents added to the glaze, and $R$ values.

heat resistance of the antimicrobial agent was improved by co-doping with $\mathrm{Zr}$ and $\mathrm{Ag}$ remained sufficient to indicate an antimicrobial effect. For this sample, ingredient analysis by XRF was carried out, but Ag was unable to be detected because of the detection limit of the XRF spectrometer. On the other hand, the $R$ values decreased with increasing $\mathrm{Zr}$ content, because $\mathrm{Ag}$ content decreased relatively. In this study, the antimicrobial agent of $\mathrm{Ag} 75 \% \mathrm{Zr} 25 \%$ was superior for porcelain glaze, in that a smaller amount of the agent was required.

\section{Conclusions}

The antimicrobial activities of a porcelain glaze with antimicrobial agent, which is generally used in the Hizen region of Japan, were investigated, and the co-doping effect of elements into the interlayer spaces of montmorillonite in order to improve the antimicrobial activity after high-temperature firing was also examined. The antimicrobial activity, $R$, of the glazes with 10 mass $\%$ antimicrobial agents fired at $1573 \mathrm{~K}$ in the reducing atmosphere was near zero, whereas those fired at $1573 \mathrm{~K}$ in the oxidizing atmosphere had $R$ values in the range of 2.5-2.7, which were positive. $R$ values of the glazes with 1.0 mass $\%$ agents fired at $1573 \mathrm{~K}$ in the oxidizing atmosphere were greater than 2.0. The sample doped at only 0.2 mass \% of $\mathrm{Ag} 75 \% \mathrm{Zr} 25 \%$, which included only 0.008 mass $\% \mathrm{Ag}$ in the glaze, was clearly positive. Co-doping of the antimicrobial agent with zirconium improved its heat resistance. The XRF profile of the sample by oxidation firing showed $\mathrm{K} \alpha$ and $\mathrm{K} \beta$ peaks of $\mathrm{Ag}$, but those of the sample by reduction firing did not. The reason why $\mathrm{Ag}$ disappeared from the glaze by reduction firing is not clear at present.

\section{References}

1) Ministry of Health, Labor, and Welfare, "Shokuchudoku Toukei Shiryou," http://www.mhlw.go.jp/topics/syokuchu/ 04.html.

2) I. Ahmed, D. Ready, M. Wilson and J. C. Knowles, J. Biomed. Mater. Res., Part A, 79A, 618-626 (2006).

3) M. Rivera-Garzab, M. T. Olguín, I. García-Sosaa, D. Alcántaraa and G. Rodríguez-Fuentes, Microporous Mesoporous Mater., 39, 431-444 (2000).

4) T. N. Kim, Q. L. Feng, J. O. Kim, J. Wu, H. Wang, G. C. Chen and F. Z. Cui, J. Mater. Sci.: Mater. Med., 9, 129-134 (1998).

5) F. Ohashi and A. Oya, J. Antibact. Antifungal Agents, 20, 525530 (1992).

6) F. Ohashi, A. Oya, L. Duclaux and F. Beguin, Appl. Clay Sci., 12, 435-445 (1998).

7) G. Auer et al., "Industrial Inorganic Pigments," Ed. by G. Buxbaum and G. Pfaff, Wiley-VCH Verlag GmbH \& Co. KGaA, Weinheim (2005) pp. 129-130.

8) A. L. Costa, F. Matteucci, M. Dondi, I. Zama, S. Albonetti and G. Baldi, J. Eur. Ceram. Soc., 28, 169-176 (2008).

9) http://www.kohkin.net/.

10) P. K. Hurlburt, O. P. Anderson and S. H. Strauss, J. Am. Chem Soc., 113, 6277-6278 (1991).

11) J. Du and Y. Fujii, Phys. Chem. Chem. Phys., 3, 5237-5241 (2001).

12) I. Rabin and W. Schulze, J. Phys. Chem. B, 108, 14575-14578 (2004). 